our Constitution, Elton becomes President next year, having served in 1984 as First Vice President and President Elect. Positions that must be filled are First Vice President, Second Vice President, Secretary, and Treasurer. The Vice Presidents serve for one year, and the Secretary and Treasurer for two. Candidates put forward by the Nominating Committee are profiled in this issue of the Bulletin. Each has served the Society well in other capacities. Their level of commitment in these positions must be great, and their challenges will not be easy, but each has demonstrated through past action the dedication and ability necessary to provide leadership for the Society.

The Nominating Committee has also prepared an excellent slate of candidates for the five positions that will become vacant on the Society's Council in 1985. The Council is the Society's governing body, and the decisions it makes determine the Society's future growth and direction. Each candidate has served the Society previously in some capacity. As the terms of Councilors run for three years, the votes cast in this election will influence the Society for years to come.

You will receive a ballot and other election materials from the Society shortly. Your vote is one of your most important privileges and responsibilities as an MRS member. I urge you to participate in this process, which will shape the future of the Materials Research Society.

\section{Changes to the Constitution}

The Society's Constitution was drafted several years ago. Since then the MRS has undergone enormous growth in membership, and substantial changes in activities and composition. As a result, several changes to the Constitution must be made for it to be consistent with our present structure. The Membership Committee, under the direction of Dick Schwoebel, has drafted proposed changes to the Constitution in order to accomplish this goal. Ed Beauchamp has made major contributions to this effort. These changes will be submitted to you, our members, for ratification. When you receive this information please consider it carefully and register your vote promptly.

\section{Our Annual Fall Meeting}

The Fall Meeting in Boston Nov. 26-30 promises to be the largest and best in the history of the Materials Research Society. More than 950 presentations will be made in the 16 topical symposia that comprise the technical program. Attendance is expected to be approximately 2,000 scientists and engineers. For the first time at an MRS meeting, a major Equipment Show will be included, and a formal job placement service will be provided. An expanded schedule of nine short courses will be offered. Articles describing the meeting and show will appear in the October issue of Physics Today and Semiconductor International, and other articles will appear in forthcoming issues of several other trade journals. Dozens of people have made major contributions to the planning of this meeting. If you haven't already, make plans now to attend-and participate in-the Boston meeting. It is the premier meeting in the world for materials professionals.

I hope to see you there.

\section{C.W. "WOODY" WHITE President}

\title{
HYDROTHERMAL REACTIONS
}

\section{MRS-Sponsored Second International Symposium \\ Set To Be Held In August, 1985, At Penn State}

The Second International Symposium on Hydrothermal Reactions will be held Aug. 12-14, 1985, at The Pennsylvania State University, University Park, Pennsylvania. Growing out of meetings in Sweden and Japan, the conference is intended to bring together scientists active in research on high pressure aqueous and related chemical systems. Included will be applications to hydrothermal geochemistry, reactions used to prepare electronic materials and ceramics, hydrothermal crystal growth, near- and supercritical separations, corrosion chemistry, and the physical chemistry of fluids at high pressures and temperatures. It is sponsored by the Materials Research Society and other organizations.

\section{Nobel Symposium}

During the Nobel Symposium on "The Chemistry and Geochemistry of Solutions at High Temperatures and Pressures" in Sweden in 1979, participants became keenly aware that periodic meetings among chemists, geochemists, materials scientists, and others actively investigating hydrothermal systems could substantially enhance the rapid sharing of information among researchers. The symposium concluded with a discussion of means by which such interaction would be possible (see p. 541, Nobel Symposium Proceedings, Physics and Chemistry of the Earth, volumes 13 and 14, edited by D.T. Richard and F.E. Wickman).

In response, Professor Shigeyuki Somiya of the Tokyo Institute of Technology and his associates organized the First International Symposium on Hydrothermal Reactions in Yokohama in 1982 (Proceedings volume distributed by Gakujutsu Bunken Fukyu-kai, Tokyo Institute of Technology, Ookayama, Meguro, Tokyo 152, Japan). This meeting was attended by 167 participants, and at its conclusion it was proposed that the series be continued triennially. The site of the Second International Symposium was designated to be The Pennsylvania State University.

\section{[Continued on Page 12]}




\section{Nine Short Courses At The Fall Meeting Of The MRS Will Cover A Broad Range Of Materials Research Techniques}

The curriculum of an expanded offering of nine short courses to be offered in connection with the MRS Fall Meeting in Boston has been set. Education Committee Cochairman David M. Zehner, Oak Ridge National Laboratory, offers this report:

\section{Purpose of Courses}

"The short-course program is designed to provide an introduction to the science and technology that will be presented at the Society's Fall Meeting. The courses will benefit those working in areas related to materials science and engineering. Both oneand two-day courses will be offered, covering a broad range of materials research techniques."

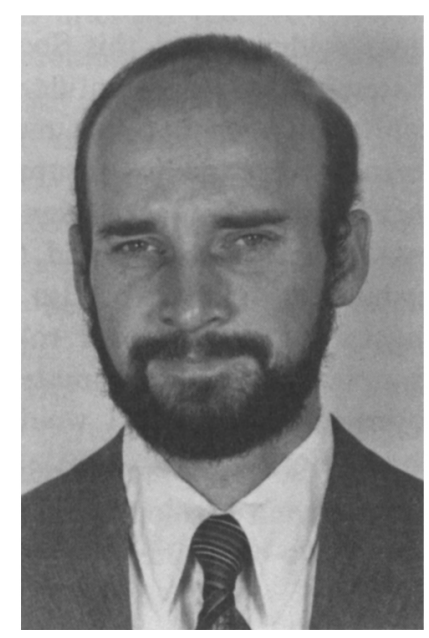

DAVID ZEHNER
The courses will be offered Friday and Saturday, Nov. 30-Dec. 1, at the conclusion of the Annual Meeting. Each will be taught be an authority in the field.

\section{Member Suggestions}

"The topics selected reflect primarily the suggestions we received from members attending MRS meetings, notably last year's Fall Meeting," Dave relates. "Immediately after that meeting, where three courses were offered, we realized that the scope would have to be substantially broadened to serve participants best. Indeed, strong interest was expressed in several areas we were not able to offer courses in this year, basically because scheduling commitments made it impossible to obtain the best faculty. We expect that such areas will be available next year, as every indication is the short courses are extremely popular and useful, and will continue to grow in number, variety, and quality."

\section{The Short Courses}

The courses to be offered, and their instructors, are:

- "Surface and Thin Film Analysis," L.C. Feldman, AT\&T Bell Laboratories, and J.W. Mayer, Cornell University. Nov. 30-Dec. 1.

- "Ion Beam Modification of Non-semiconductors," J.K. Hirvonen, Zymet, Inc. Dec. 1.

- "Ion Implantation and Rapid Thermal Annealing," T.E. Seidel, AT\&T Bell Laboratories. Nov. 30.

- "Liquid Phase Epitaxy Techniques," L.R. Dawson, Sandia National Laboratories. Nov. 30-Dec. 1.

- "Vapor Phase Epitaxy," H.M. Cox, Bell Communications Research. Nov. 30.

- "Molecular Beam Epitaxy," C.E.C. Wood, GEC Hirst [Continued on Page 11]

\section{HYDROTHERMAL}

\section{[Continued from Page 3]}

The Second International Symposium is being planned to follow the same pattern by included both invited and contributed papers from scientists of diverse disciplines who have a common interest in hydrothermal reactions. These include geochemists, crystal growers, hydro-metallurgists, materials scientists, physical chemists, and others. If necessary, attendance from the host country may be limited to preserve the valuable strong international flavor of past symposia.

\section{Symposium Organizers}

The symposium is being organized by co-chairmen H.L. Barnes, Department of Geosciences, The Pennsylvania State University, and R.A. Laudise, Physical and Inorganic Chemistry Research Laboratory, AT\&T Bell Laboratories. International advisers are Professor E.U. Franck, Institut für Physikalishe Chemie und Electrochemie, Universität Karlsruhe; Professor I.L. Khodakovsky, Vernadsky Institute of Geochemistry and Analytical Chemistry, Moscow; Dr. R.E. Mesmer, Chemistry Division, Oak Ridge National Laboratory; Professor K.S. Pitzer, Department of Chemistry, University of California, Berkeley; Professor Shigeyuki Somiya, Hydrothermal Synthesis Laboratory, Tokyo Institute of Technology, and Dr. H.S. Yoder Jr., Geophysical Laboratory, Carnegie Institution of Washington.

\section{Sponsorship}

In addition to the Materials Research Society, sponsorship has been arranged from the International Association on Geochemistry and Cosmochemistry, and the International Association for the Advancement of High Pressure Science and Technology. Sponsorship is expected from the International Organization of Crystal Growers, the International Association for the Properties of Steam, and the International Union on Pure and Applied Chemistry.

The symposium, to be held in the Conference Center of The Pennsylvania State University, follows a Gordon Conference on Inorganic Geochemistry of Mineral Deposits scheduled for Aug. 5-9 in New England. 